\title{
PERIÓDICOS SOBRE POLÍTICAS PÚBLICAS DE JUVENTUDE
}

\author{
Priscila Rodrigues dos Santos ${ }^{1}$; Frederico Oliveira ${ }^{2}$; Rafael Fernandez ${ }^{3}$; Janinne Barcelos ${ }^{4}$; \\ Ronnie Fagundes de Brito ${ }^{5}$; Milton Shintaku
}

\author{
Como citar: \\ SANTOS, P. R.; OLIVEIRA, F.; FERNANDEZ, R.; BARCELOS, J.; BRITO, R. F.; SINTAKU, M. Periódicos \\ sobre políticas públicas de juventude. In: ABEC MEETING, 1, 2017, Curitiba. Anais... Curitiba: Associação \\ Brasileira de Editores Científicos, 2017. p. 61-65. \\ http://dx.doi.org/10.21452/abecmeeting.2017.011
}

\begin{abstract}
Resumo: As políticas públicas de juventude (PPJ) são um tema essencialmente multidisciplinar, cujas discussões em âmbito federal acontecem na Secretaria Nacional de Juventude, em parceria com os ministérios. A diversidade de definições conceituais e a transversalidade com a qual o tema é tratado torna complexa a tarefa de determinar os principais periódicos que discutem as PPJ, já que estes podem ser vinculados a diferentes disciplinas e instituições. Assim, o objetivo do presente estudo é levantar os periódicos indexados no SciELO que formam o núcleo de publicações sobre o tema. Trata-se, portanto, de um estudo que alinha os preceitos da Biblioteconomia, especialmente aqueles envolvidos na formação de bibliografias especializadas. Os resultados revelaram que as disciplinas de saúde, educação, ciências sociais e ciências humanas publicam mais artigos sobre o tema, o que ratifica a multidisciplinaridade do estudo sobre as PPJ. Revela também que trata-se de um campo fértil para estudos, por sua amplitude, oportunidades para várias pesquisas e periódicos para publicação.
\end{abstract}

Palavras chave: Políticas de Juventude. Periódicos científicos. Secretaria Nacional de Juventude.

Abstract: Public policies of youth (PPJ) are an essentially multidisciplinary theme, whose federal discussions take place in the National Youth Secretariat, in partnership with ministries. A diversity of concepts and a transversality with which the subject is treated makes it difficult to determine the main periodicals that discuss as PPJs, since these can be linked in different disciplines and institutions. Thus, the objective of the present study is to raise indexed journals not SciELO that form the nucleus of publications on the topic. It is, therefore, a study that aligns the precepts of Librarianship, especially those involved in the formation of specialized bibliographies. The results revealed that as disciplines of health, education, social sciences and human sciences publish more articles on the subject, which ratifies a multidisciplinarity of the study on how PPJ. It also reveals that it is a field for studies, because of its breadth, opportunities for various researches and periodicals for publication.

Keywords: Policies of youth. Scientific journals. National Secretariat of Youth

\section{INTRODUÇÃO}

O tema juventude ganhou força no debate sobre políticas públicas no Brasil a partir da década de 1990. Como consequência do processo democrático pelo qual passou o país, e também por pressão dos movimentos sociais pela garantia e expansão dos direitos de cidadania, as questões juvenis foram paulatinamente colocadas nas agendas governamentais. Um importante desdobramento deste cenário, no âmbito do Governo Federal, foi a criação da Secretaria Nacional de Juventude (SNJ) - responsável por programas e ações específicas para esta faixa etária - e, também, o aprofundamento dos debates e reflexões no contexto acadêmico.

De acordo com o Plano Nacional de Juventude (PNJ), a juventude é constituída por pessoas com idade entre 15 a 29 anos que, segundo o censo de 2010 do Instituto Brasileiro de Geografia e Estatística (IBGE), compõem uma parcela significativa da população brasileira 
SANTOS, P. R.; OLIVEIRA, F.; FERNANDEZ, R.; BARCELOS, J.; BRITO, R. F.; SINTAKU, M.

"Periódicos sobre políticas públicas de juventude"

com mais de 32 milhões de pessoas e ampla diversidade de etnias, raças, culturas, idiomas, religiões, condições social e econômica. Toda esta pluralidade faz com que o conceito de juventude se apresente como um tema complexo e singular, muitas vezes marcado pela falta de consenso sobre o que vem a ser juventude.

Para a academia, a juventude deve ser considerada de modo multidisciplinar, com estudos sobre a educação, a saúde, a psicologia, o direito, entre outros. O governo, por sua vez, vê a juventude como um tema multiministerial, com o desenvolvimento de ações pelos ministérios da educação, trabalho, saúde e as demais pastas. Pela amplitude de atuação destas políticas, torna-se um desafio agrupar a literatura técnico-científica sobre o tema juventude, mesmo que trate de um tema em comum. Sabe-se que disciplinas distintas possuem canais de disseminação da informação diferentes: enquanto as humanidades possuem preferência por livros, as disciplinas tecnológicas preferem eventos. No entanto, quase todas as áreas do conhecimento publicam artigos em periódicos, o que pode destacar um núcleo de revistas que disseminam determinados temas.

Nesse contexto, o presente estudo busca levantar os periódicos que publicam artigos sobre o tema PPJ, de forma a descrever o panorama de publicações do tema. Dada a relevância das PPJ para o desenvolvimento social do país como um todo e o protagonismo desta temática nas discussões acadêmicas, acredita-se na necessidade de conhecer os periódicos que abordam estas questões e com isso, contribuir com os pesquisadores e gestores que atuam nessa temática, tanto para publicar os estudos, quanto ter uma bibliografia especializada confiável.

Políticas Públicas de Juventude

Em um estado democrático, as políticas públicas orientam as ações governamentais. Lima (2012), em análise multifacetada das políticas públicas, destaca que são resultados de construções coletivas, que afetam a vida cotidiana da sociedade a qual atuam. Nesta mesma linha, Souza (2006), numa visão mais social, defende que as políticas públicas atuam na identificação e solução de problemas.

Para Derani (2004) as políticas públicas podem avaliar o grau de desenvolvimento da sociedade, na medida em que representam as orientações que interferem nos comportamentos sociais. Quanto às Políticas Públicas de Juventude (PPJ), Ribeiro (2006) as considera como um conjunto de princípios, estratégias e ações que atendem às ansiedades dos jovens, em seus diversos contextos.

A partir da compreensão de que os jovens demandam projetos e programas governamentais de atuação mais ampla e específica, em julho de 2005 foi criada a Secretaria Nacional de Juventude (SNJ), vinculada diretamente à Presidência da República (PR). A 
SANTOS, P. R.; OLIVEIRA, F.; FERNANDEZ, R.; BARCELOS, J.; BRITO, R. F.; SINTAKU, M.

"Periódicos sobre políticas públicas de juventude"

percepção da necessidade da SNJ e seu apoio às Políticas Públicas de Juventude (PPJ) é compartilhada por Lobato (2014), na medida em que a autora afirma que as PPJs atuam de forma intersetorial. Não apenas no Brasil essa afirmação encontra lastro: Afonso (2013) recorre ao Tratado de Maastricht (assinado pela União Européia em 1992), ressaltando que as PPJs são transversais e devem atuar nas necessidades dos jovens.

Como forma refinada de políticas públicas, as PPJ apresentam as mesmas complexidades, na medida em que a juventude apresenta-se de maneira multifacetada, com desafios a uma nação também jovem na retomada a sua total democracia.

\section{METODOLOGIA}

O estudo apresenta-se com abordagem mista, na medida em que coleta informações de forma quantitativa, mas a analisa de forma qualitativa, numa forma que Creswell (2007) denomina de pesquisa aninhada. Possui, também, características de levantamento de bibliografia especializada, alinhadas aos preceitos e técnicas de pesquisa da Biblioteconomia.

Foi realizada pesquisa na base Scientific Eletronic Library Online (SciELO), considerando apenas artigos publicados em revistas brasileiras entre 2005 - ano de fundação da Secretaria Nacional de Juventude - e 2017. Foram utilizadas, como estratégia de busca, os termos "juventude AND Secretaria Nacional da Juventude" (1 artigo), “juventude AND políticas públicas” (51), “juventude AND serviço público” (3), “juventude AND políticas sociais" (26), "juventude AND programas de juventude" (18) e "juventude AND políticas públicas de juventude" (45). Posteriormente, os resultados foram tabulados em planilha eletrônica, a fim de se excluir artigos repetidos. Após esta etapa, restaram 74 artigos.

A seleção da base do SciELO deve-se aos aspectos gerais utilizados na indexação, que garantem certa qualidade aos periódicos lá disponíveis. Com isso, ela apresenta uma amostra significativa dos periódicos e artigos publicados sobre as PPJ. Cabe ressaltar, no entanto, que muitas revistas, principalmente das humanidades e ciências sociais, não são indexadas pelo SciELO. Deste modo, o universo de periódicos que discutem o tema deve ser bem maior.

\section{RESULTADOS}

De acordo com os resultados há, no Brasil, pelo menos 39 periódicos que publicaram um total de 74 artigos com temas voltados para PPJ, que formam a amostra de publicações analisada. Desta amostra, 25 revistas publicaram apenas um artigo, o que pode ser uma publicação esporádica, não significativa para os objetivos desta pesquisa. Assim, o estudo 
focou-se nas seis revistas que publicaram $43 \%$ dos artigos, que podem representar o núcleo de revistas que disseminam informações sobre PPJ.

As duas revistas que publicaram sete artigos representam-se mais produtivas, sendo que ambas estão relacionadas à saúde. Estes periódicos são vinculados à Associação Brasileira de Saúde Coletiva e à Associação Paulista de Saúde Pública. Verifica-se certo interesse em PPJ pelas disciplinas de Saúde, com publicações em revistas vinculadas à associações, o que não é tão comum, já que parte significativa dos periódicos é mantida por universidades.

As revistas que publicaram cinco artigos são mantidas por universidades, sendo uma delas da Universidade de São Paulo (USP) e a outra, da Universidade Federal de Santa Catarina (UFSC). Estas revistas são vinculadas à educação e ao serviço social, o que ratifica a multidisciplinaridade do tema. Neste grupo, as duas revistas são de universidades, mais comuns nas áreas de humanidades e ciências sociais.

As revistas que publicaram quatro artigos são vinculadas à Universidade Federal da Bahia (UFBA) e à Fundação Cesgranrio, sendo uma de educação e outra, das ciências humanas. Estes dados revelam que, tanto os autores, quanto os editores, não apresentam restrição em publicar artigos sobre PPJ, tanto aqueles com vínculo com instituições públicas quanto privadas.

Geograficamente, as revistas se concentram na região centro-sul, seguindo o padrão nacional, já que a maior parte das revistas são dessas regiões. A falta de revistas de Brasília, oriundas da Universidade de Brasília ou de algum órgão de governo, revela certo distanciamento entre a disseminação de informação sobre o tema e o centro das PPJ, que são criadas, discutidas e geridas pela SNJ e Congresso Nacional.

\section{CONSIDERAÇÕES FINAIS}

O núcleo de revistas que publicam artigos sobre PPJ é composto por períodos vinculados à saúde, educação, ciências sociais e ciências humanas, o que reflete a amplitude do tema. Estas publicações são vinculadas a associações e universidades, como ocorre com revistas que discutem outras temáticas. Na busca realizada, destaca-se a falta de periódicos ligados ao direito ou revistas mantidas por órgãos de governo, o que aponta que os estudos desenvolvidos têm características acadêmicas. 
SANTOS, P. R.; OLIVEIRA, F.; FERNANDEZ, R.; BARCELOS, J.; BRITO, R. F.; SINTAKU, M.

"Periódicos sobre políticas públicas de juventude"

O estudo revelou que o tema PPJ possui apenas seis revistas como núcleo de publicações indexadas na base do SciELO. É possível, contudo, que existam outros periódicos que discutem amplamente o tema, mas que não estão indexados nessa base. Com isso, percebe-se que se trata de um tema restrito, com pouca publicação, mesmo com a existência de interesse público e governamental, comprovado pela existência de secretaria de governo exclusivamente voltada à juventude. As PPJ apresentam, portanto, desafios e oportunidades de estudo acadêmico.

\section{REFERÊNCIAS}

AFONSO, Cláudia Marisa Dias Ferreira. Política sociais europeias para a juventude: o programa Juventude em Acção em Portugal. 2013. 92 f. Dissertação (Mestrado) Universidade Católica Portuguesa, Lisboa, 2013. Disponível em: <http://repositorio.ucp.pt/bitstream/10400.14/11952/1/Dissertação.pdf>. Acesso em: 10 out. 2017.

CRESWELL, John W. Projeto de pesquisa métodos qualitativo, quantitativo e misto. In: Projeto de pesquisa métodos qualitativo, quantitativo e misto. 2. Ed. Porto Alegre: Artmed, 2007.

DERANI, Cristiane. POLÍTICA PÚBLICA E A NORMA POLÍTICA. Revista da Faculdade de Direito Ufpr, [s.1.], v. 41, p.19-28, 31 dez. 2004. Universidade Federal do Paraná. http://dx.doi.org/10.5380/rfdufpr.v41i0.38314.

LIMA, Waner Gonçalves. Política pública: discussão de conceitos. Revista Interface (porto Nacional), Amapá, n. 5, p.49-54, out. 2012. Disponível em:

<http://www.ceap.br/material/MAT26022013171120.pdf>. Acesso em: 10 out. 2017.

LOBATO, Ana Laura (Org.). Jovens mulheres e políticas públicas. Brasília: Presidência da República, 2014.

SOUZA, Celina. Políticas Públicas: Políticas Públicas. Sociologias, Porto Alegre, v. 8, n. 16, p.20-45, jul. 2006. Semestral. Disponível em: 〈http://www.scielo.br/pdf/soc/n16/a03n16〉. Acesso em: 08 out. 2017.

RIBEIRO, Eliane et al. Diálogo nacional para uma política pública de juventude. Rio de Janeiro: Ibase; São Paulo: Pólis, 2006. 